\title{
PENCEGAHAN TERBENTUK NYA PRODUK SCALE PADA PIPA PRODUKSI AREA MINAS DENGAN INJEKSI CHEMICAL SCALE INHIBITOR
}

\author{
MUSMULIADI \\ Program Studi Teknik Mesin, Fakultas Teknik, Universitas Muhammadiyah Riau \\ Jalan Tuanku Tambusai Ujung, Kecamatan Tampan, Kelurahan Delima, Kota Pekanbaru, Riau 28291 \\ E-mail : musmuliadi1404@gmail.com
}

\begin{abstract}
Scale is a collection of deposits that become crusted and can cover holes, production tubes and valves so as to block the flow of fluid. Scale can reduce the diameter of the production pipe and cause the fluid flow to decrease so that the amount of production is reduced. In addition, the existence of a scale can cause an increase in pressure in the pipe, if the scale is too large it can cause the production pipe to burst. For that we need treatment for the scale case that occurs, how to overcome and reduce the possibility of scale formation on the inside of the pipe.

In the production facility, problems that can interfere with the distribution of crude oil (crude oil) are often encountered. This is generally caused by the formation of deposits (scale) along the distribution pipe. Scale is a solid (crust) resulting from crystallization and deposition of mineral formations with bacteria produced together with oil and gas. The scale formation is predicted because the bacteria contained in petroleum are attached to the distribution pipe to form crystal clumps.
\end{abstract}

Kata Kunci: Scale, Fluid, Treatment, Crude Oil

\begin{abstract}
Abstrak
Scale adalah kumpulan endapan yang menjadi kerak dan dapat menutupi lubang, tabung produksi dan katup sehingga menyumbat aliran dari fluida. Scale dapat memperkecil diameter pipa produksi dan menyebabkan aliran fluida mengecil sehingga jumlah produksi berkurang. Selain itu, dengan adanya scale dapat menyebabkan kenaikan tekanan didalam pipa, apabila scale terlalu besar terbentuk dapat menyebabkan pipa produksi pecah. Untuk itu diperlukan treatment untuk kasus scale yang terjadi, cara mengatasi serta mengurangi kemungkinan terbentuknya scale pada bagian dalam pipa.

Pada bagian fasilitas produksi sering di jumpai adanya masalah-masalah yang dapat mengganggu pendistribusian minyak mentah (crude oil). Hal ini umumnya di sebabkan oleh terbentuknya endapan ( scale) di sepanjang pipa distribusi. Scale merupakan padatan (kerak) hasil kristallisasi dan pengendapan mineral air formasi bersama bakteri yang terproduksi bersama minyak dan gas. Terbentuknya scale di prediksi karena bakteri yang terkandung di dalam minyak bumi yang melekat di dalam pipa distribusi sehingga membentuk gumpalan kristal.
\end{abstract}

Kata Kunci: Scale, Fluida, Perawatan, Minyak Menta

\section{Pendahuluan}

Indonesia merupakan negara yang kaya akan sumber daya alam. Sumber daya alam yang terdapat di Indonesia misalnya minyak bumi dan gas bumi. Hal ini menyebabkan banyak perusahaan yang tertarik untuk memanfatkan sumber daya alam yang terkandung di dalamnya. Salah satu pemanfaatan sumber daya alam khususnya di Riau adalah eksploitasi minyak bumi yang dilakukan oleh PT. XX Indonesia.

Sebagai sumber energi utama, minyak bumi sangat dibutuhkan oleh masyarakat untuk memenuhi kebutuhan. Minyak yang berasal dari dalam bumi diangkat ke permukaan dengan dua cara, yaitu natural lift dan artificial lift (Chilingar,G.V., et al.2008). Natural lift merupakan proses pengangkatan minyak bumi secara alami tanpa adanya tenaga bantuan, hal ini disebabkan karena tekanan reservoir yang besar 
dari dalam sumur produksi (Chilingar,G.V., et al.2008). Artificial lift merupakan pengangkatan yang dilakukan dengan bantuan peralatan sebagai sumber tenaga, hal ini disebabkan karena rendahnya tekanan reservoir dari dalam sumur sehingga tidak mampu mengangkat minyak bumi secara alam(Chilingar,G.V., et al.2008). Setelah dipompa, fluida hasil produksi yang mengandung minyak, air dan gas akan dikumpulkan di gathering station atau stasiun pengumpul (Chilingar,G.V.,et al.2008).

Pada produksi minyak di PT.XX Indonesia sering menghadapi pembentukan kerak atau scale pada bagian dalam pipa produksi dan beberapa tempat lainya yang dilewati fluida secara terus menerus. Scale yang terbentuk akan membentuk kerak dan dapat menutupi lubang, tabung produksi dan katup sehingga menyumbat aliran fluida hasil produksi. Dengan adanya scale, dapat menyebabkan aliran fluida mengecil sehingga jumlah produksi berkurang dan dapat menyebabkan kenaikan tekanan di dalam pipa tersebut yang dapat mengakibatkan pipa produksi pecah. Untuk memonitoring scale yang terbentuk di dalam pipa produksi dilakukan treatment chemical pada sistem pemipaan.

Penelitian ini melakukan memonitoring scale dengan memasukkan treatment chemical dan mengevaluasinya, kadar kerak tersebut dengan menggunakan coupon scale di permukaan bagian dalam pipa produksi.

\section{Metodologi}

Bahan dan Alat Penelitian

Bahan yang akan digunakan dalam penelitian ini adalah :

a. Scale inhibitor

Scale inhibitor adalah bahan kimia yang diinjeksikan ke dalam system dengan tujuan untuk melapisi permukaan dalam pipa dengan lapisan anti scale / kerak sehingga pipa terhindar dari scale. Scale inhibitor yang digunakan di Minas field adalah Gyptron ST- 4351. Lembaran material safety data sheet ( MSDS ) Scale inhibitor dapat dilihat pada lampiran 1.

a. Bahan pembersih Scale Coupon setelah dicabut yaitu Toluene, HCL $15 \%$, Sodium Carbonate $\left(\mathrm{Na}_{2} \mathrm{CO}_{3}\right) 5 \%$, deterjen, Acetone yang sudah jenuh air. b. Coupon Scale

Keping metal sederhana dan berlobang dari yang besar sampai yang kecil yang di masukkan dalam suatu sistem untuk mengevaluasi Scalling /kerak yang terbentuk pada sistem. Scale Coupon yang dipasang adalah tipe plat coupon yang berlobang - lobang kecil.

Selagi diarea PT. XX Indonesia Standart Coupon yang digunakan NACE RP 0775-99 di Area produksi minas adalah (AISI 1018, carbon steel dengan kandungan carbon $0,18 \%$ ).
Alat yang digunakan dalam penelitian ini adalah :

1. Pelengkap Coupon Scale

-Holder

Pemengang yang didesain sedemikian rupa agar coupon bias terisolasi dari strukturnya . jika coupon dan strukturnya secara elektrik berhubungan maka Scale coupon secara normal akan bertambah dari berat awal atau sisa strukturnya.

\section{-Insulator}

Adalah sekeping bahan plastic yang tahan terhadap panas biasanya terbuat dari polimer yang berguna untuk mengisolasi permukaan coupon dari holdernya agar tidak saling berhubungan satu sama lain .

\section{- Coupon Stick dan Housing Stick}

Berbentuk pipa padat stainlesstil dengan diameter antara $1 / 2$ inch $\mathrm{s} / \mathrm{d} 3 / 4$ inch, panjangnya adalah 2 kali lebar diameter pipa yang akan dipasang coupon. Pada ujung pipa terpasang coupon holder dan pada ujung lainya terpasang " $\mathrm{T}$ " untuk menahan proses selama pencabutan dan pemasangan coupon.

Pada bagian batang Stick terpasang Housing, yang berfungsi untuk menahan sekaligus tempat penghubung dengan valve yang menempel di pipa yang akan dipasang coupon.

\subsection{Prosedur dan Pelaksanaan Penelitian}

Variabel yang dapat dari penilitian ini adalah : a) Konsumsi chemical rata-rata (Chemical consumption rate) satuanya adalah GPD (Gallons Per Days) Pada 2 (Dua) spot injection chemical yaitu : sumur A dan sumur B,yang jarak spot injeksi nya berjahuan .Konsumsi chemical scale inhibitor Giptron ST-4351 yang telah di injeksikan pada masing masing spot injection chemical di rata-ratakan, selama pemasangan coupon yaitu dua bulan atau 60 hari.

Konsumsi chemical scale inhibitor ini bisa dilihat setiap hari pada kenco Sigh Glass yang dipasang di injecition point (spot injeksi chemical). Standar (target) Chemical consumtion rate maksimal yang ditetapkan oleh PT. $X X$ Indonesia untuk masing - masing spot injction chemical ini berbeda - beda, tergantung produksi air pada sumur produksinya, yaitu : spot injecton 8E-15, standarnya (target) adalah 0,5 GPD, 8D-32E standarnya (target) 1 GPD.

a. Scale rate satuanya adalah $\mathrm{mg} / \mathrm{ft}^{2}$ (milligram perfit kuadrat) spot coupon yang dipasang harus memliki aliran yang searah dengan spot injection chemical, yaitu spot coupon 9C - 46, Surge Tank-1. 
Scale Coupon harus dipasang menghadang fluida dalam sistim selama dua bulan yaitu 60 hari, berbeda dengan coupon corrosion dipasang searah dengan fluida yang mengalir. Standar atau target yang telah ditentukan untuk Scale rate maksimal yang ditentukan oleh perusahaan atau PT.XX Indonesia untuk Coupon Scale $\mathrm{Mg} / \mathrm{ft} 2$ perday. Tabel untuk hubungan target pemakaian atau konsumsi chemical yang telah ditentukan pada spot injeksi dan laju fluida Scale pada spot coupon yang ditentukan PT.XX Indonesia bisa dilihat pada tabel Dibawah ini.

Tabel 3.1 konsumsi chemical scale pada spot injeksi chemical dan spot coupon scale.

Sumber : PT. XX Indonesia ( 2018 )

Makna tabel diatas ialah scale inhibitor ST4351 merupaka zat kimia untuk mencegah terjadinya scale pada pipa di injeksikan pada spot injection chemical 8D-32E untuk monitoring couponnya dipasang atau diletakan pada tempat coupon ST.1 sebab memiliki jalur atau aliran searah ,sehingga pertumbuhan scale yang terjadi di semua pipa $8 \mathrm{D}-32 \mathrm{E}$ dapat dilihat dan dianalisa dengan cara scale coupon yang dipasang di tempat ST-1 tersebut. Begitu juga dengan tempat atau spot injection chemical 8C-15, tempat atau spot coupon nya ialah 9C-46 .

\subsection{Pemasangan Scale Coupon}

Dalam pemasangan scale coupon ada beberapa macam teknis yang harus diperhatikan yaitu:

1. Pilih pipa yang lurus dan panjang.

2. Apakah well tersebut sudah di injeksikan scale inhibitor.

3. Setelah kita survey dilapangan, pastikan posisi scale coupon monitoring station. Untuk menentukan tempat atau posisi coupon tersebut kita harus memperhatikan nya yaitu:

- $\quad$ sebelum jumper line yaitu Fluida masuk ke pipa (main line)

- $\quad$ tempat yang mendatar, kalau bisa di well WIW (water injeksi well)

- Beri tanda atau di cat putih agar mudah dalam pengerjaan hot tap nanti.

4. Bila sudah lengkap semua baru pasang scale coupon tersebut pada wing line pipa lebih kurang 0,5 $\mathrm{cm}$ dari dasar pipa sesuai SOP (standard operation prosedur) yang ada di PT. XX Indonesia.

Cara pemasangan Scale coupon

1. Pastikan terlebih dahulu tempat dimana scale coupon akan mau dipasang dan yang sudah terpasang kran 2".

2. Siapkan coupon yang mau akan dipasang dan pastikan coupon tersebut sudah ditimbang di OM\&LAB. Jangan lupa catat beratnya sesuai kode dan nomor coupon.
3. Kemudian Pasang coupon pada stik nya ( “ Rod String Coupon Holder" )

\begin{tabular}{|c|c|c|c|c|}
\hline \multirow{2}{*}{ NO } & \multicolumn{2}{|c|}{$\begin{array}{c}\text { CHEMICAL } \\
\text { CONSUMPTION }\end{array}$} & \multicolumn{2}{c|}{ SCALE RATE } \\
\cline { 2 - 5 } & $\begin{array}{c}\text { Spot } \\
\text { Injction }\end{array}$ & $\begin{array}{c}\text { Target } \\
(\text { GPD })\end{array}$ & $\begin{array}{l}\text { Spot } \\
\text { Coupon }\end{array}$ & $\begin{array}{c}\text { Target } \\
\text { mg/ft }^{2}\end{array}$ \\
\hline 1. & $8 \mathrm{D}-32 \mathrm{E}$ & 1 & ST.1 & $<100$ \\
2. & $8 \mathrm{C}-15$ & 0,5 & $9 \mathrm{C}-46$ & $<100$ \\
& & & & \\
\hline
\end{tabular}

4. Tempatkan dengan benar dan pasang Scale coupon pada kran 2" yang sudah terdapat pada pipi produksi.

5. Buka kran 2" secara perlahan dan pastikan pengunci packing sudah kuat supaya minyak dan air tidak bocor atau menyembur keluar dari selah selah packing.

6. Masukan Scale coupon tersebut kedalam pipa secara hati-hati dan pastikan coupon tersebut ditempatkan pada pipa bagian bawah.

7. Pastikan glend nut sudah mengunci pada holder coupon jika perlu pasang rantai untuk pengamannya.

\subsection{Scale Injection point.}

Injection point adalah tempat dimana chemical di injeksikan pada system,contoh pada gambar 3.11. mulai dari sini chemical berapa banyak yang akan di injeksiakan dengan menggunakan chemical pump 4300, sangat berpengaruh sekali ke efektif tidaknya performa chemical st- 4351 tersebut.

Cara atau langkah kerjanya adalah:

1. Harus melakukan pengecekan setiap hari di spot injeksi chemical scale tersebut yang banyak nya dua spot injeksi dan mencatat berapa level yang ada di gelas ukur (kenco sight glass), supaya bisa melihat chemicala pump benar - benar memompa dengan baik dan sempurna.

2. Kemudian catat stok chemical yang ada di sight glass kenco dan juga pastikan berapa banyak (rate) chemical yang di injeksikan . maka dari itu untuk mengetahui rate chemical yang di ineksikan harus dengan menggunakan jam tangan dan stopwatch sebagai pencatat waktu.

- Siapkan sebuah jam tagan atau stopwatch

- Tekan stoper level atau tuas handle kebawah supaya aliran chemical terstop dari drum

- Ambil spidol untuk menandai level chemical awal atau level tertinggi pada sight glass kenco 
- Tekan atau push dan mulai melakukan tes lebih kurang selama sembilan ketukan atau 15 detik, dalam sop 1 menit.

- perhitungan terakhir pada 15 detik tandai level yang ada pada sight glass yang rendah.

- kemudian lepaskan handle kenco tersebut.

- kemudian kita bisa menghitung penurunan chemical yang ada di sight glass yang ada di skala kenco bagian dalam ,perhitungan nya gallon perday. Level selisih dalam satu menit yaitu sama dengan jumlah gallon dari chemical tersebut yang dipakai dalam satu hari . Hasil injeksi chemical ini mulai dicatat tanggal 4 februari 2020 , satu hari setelah pemasangan coupon monitoring selama 60 hari yaitu dua bulan lama masa pemasangan chemical coupon di piapa produksi.

- Hasil pemakaian scale inhibitor giptron ST

- 4351 ini kemudian dirata ratakan untuk masing masing spot injeksi chemical selama waktu pemasangan coupon scale didalam pipa produksi.

\subsection{Pencabutan Coupon Scale - 4351}

Coupon ini hanya bisa dipakai sekali saja, namun pencabutan scale coupon dilakukan 60 hari setelah dipasang didalam pipa produksi.

Cara pencabutan Coupon Scale adalah:

1. Longgarkan sedikit saja nut lock stick coupon, agar gas atau bisa dirilis supaya tidak menyembur.

2. Tarik stick perlahan lahan sambil ditahan supaya pencabutan yang dilakukan sewaktu waktu bisa saja terjadi pressure atau tekanan balik dari dalam pipa.

3. Setelah stick terangkat keatas tutup ball valve dengan rapat supaya tidak ada fluida yang keluar.

4. Buka perlahan lahan hausing pada ball valve tersebut ,hal ini bisa sekaligus untuk merilis fluida atau minyak yang terperangkap / terkurung pada hausing.

5. Lepaskan scale coupon dan ganti dengan yang baru .

Coupon scale tidak boleh dipegang oleh tangan secara langsung, karna bisa mengakibatkan menaikan atau menurunkan scale pada coupon ,tergantung tangan tersebut basah keringat, berminyak dan kotor.

Sewaktu mau melepaskan coupon dari holdernya coupon tidak boleh dipegang dengan tangan telanjang / terbuka karna bisa menurunkan juga bisa menaikan scale karna tangan bisa berkringat,sedangkan keringat kita mengandung garam atau tangan kita berminyak sewaktu membuka holder dan coupon tersebut.

\subsection{Analisa Scale}

\section{SOP Ananlisa Scale Coupon}

1. Perhatikan scale coupon, lihat warna dan catat kotoran atau kerak yang terbentuk ,Cabut atau buka kacang - kacang (insulator) penahan yang menempel pada coupon dengan ragum atau tang kemudian rendam kedalam toluene supaya bersih dari minyak yang menempel.

2. Kemudian rendam scale coupon kedalam HCL $15 \%$ selama 1menit, kemudian cuci dengan sabun special coupon bisa di ulang mencuci nya sebanyak dua kali.

3. Ambil coupon scale tersebut rendam dengan $\left(\mathrm{Na}_{2} \mathrm{CO}_{3}\right)$ lebih kurang selama 2-5 menit. Kemudian cuci dengan sabun spcial coupon atau deterjen .

4. Rendam coupon ke dalam Acetone lalu masukan kedalam desikator selama kurang lebih 15 menit.

5. Kemudian timbag berat bersih scale coupon tersebut.

6. Menggunakan aplikasi Langelier Saturation Index untuk menghitung Saturated Index (SI) untuk mengetahui kondisi kandungan air formasi

$$
\text { Standar atau target coupon Scale yang }
$$

diperbolehkan oleh pt XX indonesia

yaitu: $<100 \mathrm{mg} / \mathrm{ft}^{2}$.

Tujuan dari penelitian ini adaalah untuk mengetahui scale pada permukaan dalam bagian pipa. Setelah dilakukan perawatan dengan bahan kimia scale inhibitor 4351 dan jumlah pemakaian chemical tersebut dengan mengunakan monitoring coupon yang dimasukan dalam pipa selama 60 hari. Scale inhibitor bekerja mencegah scale dengan cara merusak siklus pembentukan scale atau tidak membiarkan kristal scale menempel ke permukaan logam. Metode yang tepat adalah

dengan menggunakan chemical yang sesuai dengan kondisi lapangan.

Tabel 4.1 Hubungan Konsumsi Chemical Scale Inhbitor (consumsption Chemical rate) pada spot injeksi chemical dan cepat pertumbuhan scale (scale rate) pada spot coupon di area 2 produksi Minas. 
Pada tabel 4.1 dapat dilihat bahwa konsumsi chemical scale inhibitor 4351 pada masing-masing

\begin{tabular}{|c|c|c|c|c|c|c|}
\hline \multirow{2}{*}{ NO } & \multicolumn{2}{|c|}{$\begin{array}{c}\text { CHEMICAL CONSUMPTION } \\
\text { (GPD) }\end{array}$} & \multicolumn{3}{|c|}{ SCALE RATE (mg/ft $\left.{ }^{2}\right)$} \\
\cline { 2 - 7 } & $\begin{array}{c}\text { Spot } \\
\text { Injection }\end{array}$ & Target & Consumtion & $\begin{array}{c}\text { Spot } \\
\text { coupon }\end{array}$ & Target & $\begin{array}{c}\text { Scale } \\
\text { rate }\end{array}$ \\
\hline 1 & $8 \mathrm{C}-15$ & 0,5 & 0,5 & ST-1 & $<100$ & 1,2 \\
\hline 2 & $8 \mathrm{D}-32 \mathrm{E}$ & 1 & 1 & $9 \mathrm{C}-46$ & $<100$ & 1,3 \\
\hline
\end{tabular}

spot injeksi bekerja dengan baik karena konsumsi chemical scale inhibitor sesuai dengan standar ( target ) yang telah ditetapkan oleh PT XX Indonesia.

Untuk mengetahui kemungkinan scale yang terbentuk didalam pipa, dapat dilakukan dengan mengevaluasi hasil water analysis dari air formasi (air yang berasal dari sumur produksi).

1.Menggunakan aplikasi Langelier Saturation Index untuk menghitung Saturated Index (SI) untuk mengetahui kondisi kandungan air formasi.

2.Melakukan perhitungan jumlah inhibitor yang harus diinjeksikan perharinya berdasarkan banyaknya air formasi yang dihasilkan setiap harinya. 4.2 Water Analysis Data Sumur A Berdasarkan hasil water analysis di dapatkan data Sumur A Barrel Water / Day : 2554.75 Barrel

Tabel 4.2 Hasil water analysis sumur A Analisa

Satuan Hasil tes

$\begin{array}{lll}\text { Barium Sulfate (BaSO4) } & \mathrm{mg} / \mathrm{L} & 0.29\end{array}$

Calcium Sulfate (CaSo4) $\quad \mathrm{mg} / \mathrm{L} \quad 0.19$

Calcium Carbonate $(\mathrm{CaCo} 3) \quad \mathrm{mg} / \mathrm{L} \quad 1.2$

pH Lab

Sumber: PT XX Indonesia

Penentuan jenis scale yang terbentuk dapat dilihat dengan mengunakan saturationindexcalculator(https://www.lenntech.com/c alculators/langelier/ndex/langelier.htm).didapatkan hasil:

LSI = Langelier Saturation Index 1.2

Indication based on Langelier (1936)

(Indikasi berdasarkan Langelier) Water is superatured with respect to calcium carbonate (CaCo3) and scale porming may occur.(Air menjadi jenuh sehubungan dengan kalsium karbonat $\mathrm{CaCo3}$ dan pembentukan kerak dapat terjadi)

Gambar 4.1 Hasil Langelier Saturation Indek sumur A
Langelier Saturation Index menunjukkan tingkat kejenuhan air terhadap kalsium karbonat. Dikarenakan scale dipengaruhi oleh tingkat kelarutan senyawa didalam air, nilai Saturation Index senyawa dalam air dapat membantu menentukan scaling dan jenis scale yang mungkin terbentuk.

Dari hasil kalkulasi, didapatkan nilai LSI sebesar 1.2. Nilai LSI data sumur A lebih besar dari 0 yang menandakan senyawa $\mathrm{CaCO}_{3}$ berada dalam keadaan lewat jenuh (supersaturated) dan jenis scale yang terbentuk adalah calcite. Berdasarkan nilai LSI, didapatkan bahwa scale terjadi, namun korosi tidak terjadi.

Suasana basa dan temperature yang tinggi membantu proses scale terjadi lebih cepat. Scale jenis calcite paling mudah terbentuk dibandingkan jenis scale lainnya karena kemampuannya membentuk kristal dan semakin tinggi suhu, semakin rendah kelarutannya.

Indiction based on impproved Langelier by carrier(1965)

(Indikasi berdasarkan bahasa yang ditingkatkan oleh pembawa) Scale forming but not corrosive (pembentukan kerak/scale tetapi tidak korosi)

Dari hasil kalkulasi, didapatkan nilai LSI sebesar 1.3. Nilai LSI data sumur B lebih besar dari 0 yang menandakan senyawa $\mathrm{CaCO}_{3}$ berada dalam keadaan lewat jenuh (supersaturated) dan jenis scale yang terbentuk adalah calcite. Berdasarkan nilai LSI, didapatkan bahwa scale terjadi, namun korosi tidak terjadi. Suasana basa dan temperature yang tinggi membantu proses scale terjadi lebih cepat. Scale jenis calcite paling mudah terbentuk dibandingkan jenis scale lainnya karena kemampuannya membentuk kristal dan semakin tinggi suhu, semakin rendah kelarutannya.

4.4 Penanganan Scale

Berdasarkan hasil data water analysis dari produce water sumur A dan B, sebaiknya dilakukan pembersihan pipa menggunakan asam (acidizing). Biasannya untuk proses menghilangkan endapan scale yang terdapat pada pipa/peralatan produksi, pembersihan dilakukan dengan menempatkan asam diposisi scale berada dan memberinya waktu untuk bereaksi.

Selain itu, sebaiknya diinjeksikan inhibitor untuk mencegah terjadinya scale. Penambahan inhibitor ST4351 dilakukan dengan injeksi harian. Jumlah inhibitor yang diinjeksikan sebesar $5 \mathrm{ppm}-50 \mathrm{ppm}$, disesuaikan dengan kandungan mineral yang ada pada produce water. Konsentrasi inhibitor pertama yang diinjeksikan untuk mencegah scale sebesar 5ppm. Jumlah inhibitor yang harus diinjeksikan setiap harinya dapat dihitung dengan rumus :

(Rate scale inhibitor (gallon))/(Barrel Water perDay $($ gallon $)) \times 1.000 .000=$ Konsentrasi inhibitor 
Sehingga nilai Rate scale inhibitor yang harus ditambahkan perharinya untuk sumur A dan B :

Sumur A :

Total Barrel Water perDay $=2554,75$ barrel atau 107.299,5 gallon

Rate scale inhibitor $($ gallon $)=(5 \mathrm{ppm} \times 107.299,5$ gallon )/1.000.000

Rate scale inhibitor (gallon) $=0.5364$ gallon/day Untuk mencegah scale pada sumur A, sebanyak 0.5364 gallon inhibitor (relative) diinjeksikan perharinya. Namun dikarenakan keterbatasan alat untuk menginjeksi dengan jumlah tertentu $(0,5$ gallon; 1 gallon; 1,5 gallon, dll), dilakukan pembulatan untuk jumlah inhibitor. Setelah dilakukan pembulatan, jumlah inhibitor yang harus diinjeksikan setiap harinya sebesar 0.5 gallon/day.

Sumur B :

Total Barrel Water perDay $=4428$ barrel atau 185.976 gallon

Rate scale inhibitor $($ gallon $)=(5 \mathrm{ppm} \times 185.976$ gallon )/1.000.000

Rate scale inhibitor (gallon) $=0.9298$ gallon/day Untuk mencegah scale pada sumur B, sebanyak 0.9298 gallon inhibitor (relative) diinjeksikan perharinya. Setelah dilakukan pembulatan, jumlah inhibitor yang harus diinjeksikan setiap harinya sebesar 1 gallon/day.

Setelah penambahan inhibitor untuk mencegah scale, dilakukan monitoring dengan pemasangan scale coupon pada pipa dekat sumur A dan B untuk meguji keefektifan scale inhibitor yang ditambahkan.

Batasan scale inhibitor dalam menghambat kecepatan pertumbuhan scale harus kurang dari $100 \mathrm{mg} / \mathrm{ft}^{2} /$ day. Apabila melebihi,artinya jumlah scale inhibitor yang ditambahkan belum cukup untuk mencegah scale, maka ditambahkan jumlahnya sebanyak duakalinya.

\subsection{Water Analysis Data Sumur B}

Berdasarkan hasil water analysis didapatkan data Sumur B Barrel Water/Day : 4428 Barrel

Tabel 4.3. Hasil water analysis sumur B

Analisa

Satuan Hasil tes

Barium Sulfate (BaSO4)

$\mathrm{mg} / \mathrm{L} \quad 0.14$

Calcium Sulfate (CaSo4)

$\mathrm{mg} / \mathrm{L} \quad 0.88$

Calcium Carbonate ( $\mathrm{CaCo} 3)$

$\mathrm{mg} / \mathrm{L} \quad 1.3$

$\mathrm{pH} \mathrm{Lab}$

8.9
Penentuan jenis scale yang terbentuk pada sumur B sama dengan sumur A yaitu dapat dilihat dengan menggunakan Saturation Index calculator

(http:/www.lenntech.com/calculators/langelier/ndex/langelier .htm).

Dari hasil LSI didapatkan :

LSI = Langelier Saturation Index

Indication based on Langelier (1936)

(Indikasi berdasarkan Langelier) Water is superatured with respect to calcium carbonate (CaCo3) and scale porming may occur.(Air menjadi jenuh sehubungan dengan kalsium karbonat $\mathrm{CaCo} 3$ dan pembentukan kerak dapat terjadi)

Indiction based on impproved Langelier by carrier (1965)

(Indikasi berdasarkan bahasa yang ditingkatkan oleh pembawa) Scale forming but not corrosive (pembentukan kerak/scale tetapi tidak korosi)

Gambar 4.2 Hasil Langlier Saturation Index Sumur B

Dari hasil kalkulasi, didapatkan nilai LSI sebesar 1.3. Nilai LSI data sumur B lebih besar dari 0 yang menandakan senyawa $\mathrm{CaCO}_{3}$ berada dalam keadaan lewat jenuh (supersaturated) dan jenis scale yang terbentuk adalah calcite. Berdasarkan nilai LSI, didapatkan bahwa scale terjadi, namun korosi tidak terjadi. Suasana basa dan temperature yang tinggi membantu proses scale terjadi lebih cepat.

Scale jenis calcite paling mudah terbentuk dibandingkan jenis scale lainnya karena kemampuannya membentuk kristal dan semakin tinggi suhu, semakin rendah kelarutannya.

4.4 Penanganan Scale

Berdasarkan hasil data water analysis dari produce water sumur A dan B, sebaiknya dilakukan pembersihan pipa menggunakan asam (acidizing). Biasannya untuk proses menghilangkan endapan scale yang terdapat pada pipa/peralatan produksi, pembersihan dilakukan dengan menempatkan asam diposisi scale berada dan memberinya waktu untuk bereaksi.

Selain itu, sebaiknya diinjeksikan inhibitor untuk mencegah terjadinya scale. Penambahan inhibitor ST4351 dilakukan dengan injeksi harian. Jumlah inhibitor yang diinjeksikan sebesar 5 ppm-50 ppm, disesuaikan dengan kandungan mineral yang ada pada produce water. Konsentrasi inhibitor pertama yang diinjeksikan untuk mencegah scale sebesar 5ppm. Jumlah inhibitor yang harus diinjeksikan setiap harinya dapat dihitung dengan rumus :

(Rate scale inhibitor (gallon))/(Barrel Water perDay $($ gallon $) \times 1.000 .000=$ Konsentrasi inhibitor

Sehingga nilai Rate scale inhibitor yang harus ditambahkan perharinya untuk sumur A dan B : 
Sumur A :

Total Barrel Water perDay $=2554,75$ barrel atau 107.299,5 gallon

Rate scale inhibitor $($ gallon $)=(5 \mathrm{ppm} \times 107.299,5$ gallon )/1.000.000

Rate scale inhibitor (gallon) $=0.5364$ gallon $/$ day

Untuk mencegah scale pada sumur A, sebanyak 0.5364 gallon inhibitor (relative) diinjeksikan perharinya. Namun dikarenakan keterbatasan alat untuk menginjeksi dengan jumlah tertentu $(0,5$ gallon; 1 gallon; 1,5 gallon, dll), dilakukan pembulatan untuk jumlah inhibitor. Setelah dilakukan pembulatan, jumlah inhibitor yang harus diinjeksikan setiap harinya sebesar 0.5 gallon/day.

\section{Sumur B :}

Total Barrel Water perDay $=4428$ barrel atau 185.976 gallon

Rate scale inhibitor $($ gallon $)=(5 \mathrm{ppm} \times 185.976$ gallon )/1.000.000

Rate scale inhibitor (gallon) $=0.9298$ gallon $/$ day

Untuk mencegah scale pada sumur B, sebanyak 0.9298 gallon inhibitor (relative) diinjeksikan perharinya. Setelah dilakukan pembulatan, jumlah inhibitor yang harus diinjeksikan setiap harinya sebesar 1 gallon/day.

Setelah penambahan inhibitor untuk mencegah scale, dilakukan monitoring dengan pemasangan scale coupon pada pipa dekat sumur A dan B untuk meguji keefektifan scale inhibitor yang ditambahkan.

Batasan scale inhibitor dalam menghambat kecepatan pertumbuhan scale harus kurang dari $100 \mathrm{mg} / \mathrm{ft}^{2} / \mathrm{day}$. Apabila melebihi,artinya jumlah scale inhibitor yang ditambahkan belum cukup untuk mencegah scale, maka ditambahkan jumlahnya sebanyak duakalinya. Pembentukan scale ditandai dengan mulai tersumbatnya pipa akibat kenaikan pressure, lalu kenaikan pressure ini diukur oleh transduser yang berfungsi sebagai pengubah sinyal pressure yang dihasilkan menjadi sinyal listrik sehingga diolah menggunakan data processor, yaitu software Scaale Flow Loop.

\subsection{Kesimpulan}

5.1.1 Berdasarkan hasil evaluasi data water analysis sumur A dan sumur B, scale terbentuk pada pipa.

5.1.2 Berdasarkan hasil penelitian pada sumur A dan sumur B di dapat Jenis scale yang sama yaitu kalsium karbonat $\left(\mathrm{CaCO}_{3}\right)$.

5.1.3 Untuk mencegah terjadinya scale, diinjeksikan inhibitor setiap harinya. Jumlah inhibitor yang harus diinjeksikan pada sumur A sebesar 0.5 gallon/day dan pada sumur B sebesar 1 gallon/day. Untuk menguji keefektifan inhibiutor, dilakukan monitoring dengan pemasangan scale coupon.

5.1.4 Dengan adanya penginjeksian inhibitor ini maka didapat hasil produksi sumur A dan sumur B sesuai dengan yang di harapkan oleh PT.XX Indonesia

5.2 Saran

5.2.1 Monitoring dengan scale coupon selalu dilakukan pada setiap pipa yang dialiri fluida dengan kandungan mineral yang tinggi. Untuk mengetahui jenis scale yang terjadi, sebaiknya juga dilakukan analisis XRD (X-ray Diffraction ).

5.2.2 Saran untuk PT.XX Indonesia semakin besar pemakaian Inhibtor semakin bagus untuk perawatan pipa produksi.

\section{DAFTAR PUSTAKA}

[1] Chilingar, G.V., Ryan, M \& Ghazi D.A.2008. The Fundamentals of Corrosion and Scaling : A Handbook for Petroleum and Environmental Engineers. Gulf Publishing Company. Texas.

[2] Dobson, J.2013. Production Chemistry Training Course Manual. Oil Plus Publishing.Berkshire.

[3] Ezuber, H.M. 2007. Prediction of Strontium Sulfate Scale Formation in Oilified Environment. Journal of ASTM International. Vol.4 No.6.

[4] Farooqui, N.M., Sorbie, K.S \& Boak, L.S 2015. Prociding of SPE European Formation Demage. Molecular Weight Effects in Polymeric Scale Inhibitor Precipitation Squeeze Treatments. Hungary, 3-5 June.

[5] Graham, G.M., Jordan, M.M \& Sorbie, K.S.1997 Prociding of Advances in Solving Oilfield Scaling. How Scale Inhibitor Work and How this Affect Test Methodology 3rd. Aberdeen, 22-23 January.

[6] Frenier, W.,W. Review of Inorganic Scale Formation, Removal and Inhibition. Schlumberger. 2003.

[7] Harberg, T. Granbakken, D.B. Scale Formation in Reservoir and Production Equipment During Oil Recovery. SPE Production Engineering. 1992.

[8] OLI System, Inc. ScaleChem: General Introduction of ScaleChem Features. 2006.

[9] Rodriguez, Valmore and Evaristo Baron. Field Guidelines For Oilfiels Scale and Corrosion Management and Control: Mechanisms, Mitigation, and Prevention. NExT. Petronas. Malaysia. 2010.

[10] Amyx Petroleum Reservoir Engeneering, Chapter 6 Mc Graw HilJnbook Company, New York 1960

[11] Darajat, M. (t.thn.). Macam - Macam Jenis Scale. Universitas Sriwijaya Palembang 
[12] Dirjen Migas,SK No.89 KJDDJM/1994 . Ketentuan Pe]aksanaan Evaluasi Mutu Minyak Bumi.

[13]E.Brown Kermit/Beggs H. Dale, "The Technology of Artificial Lift Methods", Volume $1,1997$.

[14] http://v]advamphire.files.wordpre ss.com/2009/01/bab-04-AJ iran-Fluida-Dalam? Pipa.ppt

[15] Lestari. (2007, Juli). Problema Scale di Beberapa Lapangan Migas. Proceeding Simposium Nasional IA TMI , 25-28

[16] Amin, M. Mustaghfirin. 2013. PK. "Teknik Produksi Migas. Proses Produksi Migas". Semester IV. Kementrian Pendididikan dan Kebudayaan Republik Indonesia.
A. Kelland, Malcolm. 2012. "Production Chemicals for the Oil and Gas". Taylor and Francis Group, LLC.London

[17] Champion Technologies's Team. 2013. "Safety and Behavior Based Safety Training". Champion Technologies. Pekanbaru

[18] Champion Kurnia Djaja Technologies. 2009. "Training Modul Section 1,2, 3, 4,5, 7-1, 7-2, 7-3, 7-6". Champion Technologies. Pekanbaru.

[19] Nalco Champion 's team. 2013. "productions Chemical Training".Tacking Energy Further. NALCO Cghampion An Ecolab Company.Jakarta.

[20] Modul 5. O\&TC -HR Learning and Development.2004.Production Operation .Operator \& Technician Certification . PT.Caltex Pacific Indonesia .Jakarta.

[21] Champion Technologies .2009. "Corrosion Scale". PTChampion Kurnia Djaja Technologies.Pekanbaru.

[22]Patton, C. 1981. Oilified Water System 2 ed.Okohama. Campbeel Petroleum Series : 29-79.

[23] Siswoyo, K. E. 2005. Identifikasi Pembentukan Scale. UPN Veteran. Yogyakarta. 